Research Article

\title{
Determinants of Low Fifth Minute Apgar Score among Newborn Delivered in Jimma University Medical Center, Southwest Ethiopia
}

\author{
Bekalu Getachew $\left(\mathbb{D},{ }^{1}\right.$ Tesema Etefa $\mathbb{D}^{1},{ }^{1}$ Adissu Asefa, ${ }^{2}$ Behailu Terefe $\mathbb{D D}^{3}$ \\ and Diriba Dereje ${ }^{4}{ }^{4}$ \\ ${ }^{1}$ Department of Biomedical Sciences (Anatomy), Institute of Health Sciences, Jimma University, Jimma, Ethiopia \\ ${ }^{2}$ Department of Biomedical Sciences (Anatomy), Collage of Health and Medical Sciences, Debre Berhan University, \\ Debre Berhan, Ethiopia \\ ${ }^{3}$ Department of Pharmacy (Clinical Pharmacy), Institute of Health Sciences, Jimma University, Jimma, Ethiopia \\ ${ }^{4}$ Department of Biomedical Sciences (Physiology), Institute of Health Sciences, Jimma University, Jimma, Ethiopia
}

Correspondence should be addressed to Bekalu Getachew; bekalugetachew73@gmail.com

Received 22 November 2019; Accepted 22 February 2020; Published 5 March 2020

Academic Editor: Alessandro Mussa

Copyright (c) 2020 Bekalu Getachew et al. This is an open access article distributed under the Creative Commons Attribution License, which permits unrestricted use, distribution, and reproduction in any medium, provided the original work is properly cited.

\begin{abstract}
Background. Apgar score is currently an accepted method for newborn infant assessment immediately after delivery. Low fifth minute Apgar score was strongly associated with the risk of neonatal and infant death. Even though much has been done, still, the levels of neonatal mortality in sub-Saharan African countries including Ethiopia were significant. Therefore, this study is aimed at identifying the risk factors so as providing strategies for decreasing the morbidity and mortality of newborns and identifying determinants of low fifth minute Apgar score among newborns delivered in Jimma University Medical Center, Southwest Ethiopia, 2018. Method. Institution-based cross-sectional study was conducted involving 366 neonates delivered at Jimma University Medical Center. Data was collected by using interview questionnaire. Apgar score was assessed by standard tool at the $1 \mathrm{st}$, 5th, and 10th minutes after birth and only $5^{\text {th }}$ minute Apgar score was used as outcome variable. Consecutive sampling technique was used to select the participants. The collected data were analyzed using SPSS version 20.0. Chi-square test was done at bivariate level and $P$ value was used to select candidate variables for multivariate analysis. Finally, a $95 \%$ confidence interval was used to assess significance. Results. A response rate of this study was $95 \%$. The proportion of low 5 th minute Apgar score in this study was $11.5 \%$. Prolonged duration of labor (AOR $=15.18,95 \%$ CI: $5.51-40.27$ ), maternal history of khat use $(\mathrm{AOR}=3.21,95 \% \mathrm{CI}$ : 1.26-8.85), and low birth weight $(\mathrm{AOR}=1.65,95 \% \mathrm{CI}$ : 1.02-3.11) were predictors of low fifth minute Apgar score. Conclusion. About one tenth of newborns were having low 5th minute Apgar score. The likelihood of low $5^{\text {th }}$ minute Apgar score was found to increase with prolonged duration of labor, history of mother's khat use, and low birth weight.
\end{abstract}

\section{Introduction}

The Apgar score was proposed in 1952 as a means of rapidly evaluating the clinical status of newborn infants [1] and currently remains an accepted method for newborn infant assessment immediately after delivery [2]. Reduced Apgar score, including less than five Apgar score components, is as valuable as the full Apgar score to predict neonatal mortality [3].
Low Apgar scores was associated with increased perinatal morbidity and mortality [4]; neonatal and infant death had a strong association with low Apgar score $(<3)$ [5]. In infants with low Apgar score at $5 \mathrm{~min}$, there is increased risk of neonatal respiratory distress, need for mechanical ventilation and admission to neonatal intensive care unit [6], and also, a higher risk of childhood cancers [7].

Children with a five-minute Apgar score of 3 or less and signs consistent with neonatal encephalopathy had a significantly 
increased risk of developing minor motor impairments [8]. Low cognitive function, neurologic disability, and even subtle cognitive impairment as measured by academic performance at 16 years of age was showed to be associated with Apgar scores of less than 7 at five minutes after birth as evidenced in recent studies $[9,10]$. According to the study done in the USA, low Apgar score was associated with increased mortality in premature neonates, including those at 24-28 gestational weeks of age, and proposed to be a useful tool for clinicians in assessing prognosis of newborn [11].

The heart rate and respiratory effort components at $5 \mathrm{~min}$ are central for neonatal mortality [3]. Infants with low 5minute Apgar score have greater risk for mortality and morbidities associated with prematurity [12]. Of infants with a very low Apgar score at 5 minutes, $81 \%$ had a poor outcome. In these infants, the relative risk (RR) for perinatal mortality was 24.93 (13.16-47.20) [13]. Deaths within 24 hours were more common among infants with Apgar scores 0-3 than among infants with Apgar scores 7-10 [14]. The risk of developmental vulnerability at 5 years of age is inversely associated with the $5 \mathrm{~min}$ Apgar score across its entire range and even the score can serve as a population-level indicator of developmental risk [15].

According to sustainable development goals (SDGs), under five mortality, is planned to be reduced by $50 \%$ in WHO African region by specifically reducing newborn mortality by relying on better prevention and management of preterm birth, inpatient care, and support of newborn and postneonatal period [16]. During the Millennium Development Goal (MDG) era, many countries in Africa achieved marked reductions in under- 5 and neonatal mortality. Yet, the pace of progress toward these goals substantially varied at the national level, demonstrating an essential need for tracking even more local trends in child mortality [17]. In Ethiopia, although the target for under-five mortality rate was achieved, the targets for infant and neonatal mortality rates were just below the MDG four targets [18]. Despite a $50 \%$ reduction in childhood mortality, reduction of early neonatal death (ENND) has significantly lagged behind other Millennium Developmental Goal achievements and is a growing contributor to overall mortality in children aged $<5$ years.

Therefore, deaths in the newborn period and especially ENND are increasingly contributing to overall infant mortality at age $<5$ years [19]. Even though much has been done, still, the levels of neonatal mortality in sub-Saharan African countries were significant. One of the early neonatal assessment tools for neonatal status is Apgar score. Therefore, identifying determinants of low Apgar score is very important in early neonatal prevention of morbidity and mortality. There were no adequate published researches in Ethiopia that identified predictors of fifth minute Apgar score. Thus, this study was aimed at assessing determinants of low fifth minute Apgar score among newborn delivered at Jimma Medical Center. In addition, this study will give a new dimension in identifying the risk factors, and also provides an input for the prevention and early identification of those risks for decreasing the morbidity and mortality of newborns.

\section{Methods}

2.1. Study Area and Period. This study was conducted in Jimma University Medical Center (JUMC) which is located in Jimma town, Jimma zone, $355 \mathrm{Km}$ in the southwest of Addis Ababa, the capital city of the Ethiopia. JUMC is a 500-bedded teaching and referral hospital that provide general and specialized clinical services including maternal and childcare for about 15 million populations in southwestern part of Ethiopia. The Gynecology/Obstetric wards of the hospital, with 45 maternity beds and five delivery tables, provide 24-hour obstetrics and gynecology care to both direct and referral cases. The study was conducted from May 1 to May 30, 2018.

2.2. Study Design. An institution-based cross-sectional study was conducted among neonates delivered at JUMC.

2.3. Source Population. All neonates delivered at JUMC.

2.4. Study Population. All neonates delivered at JUMC and presented during data collection period.

\subsection{Eligibility Criteria}

\subsubsection{Inclusion Criteria}

(i) All mother/neonate index singleton live births after 28 weeks of gestation during the study period were included in the study

\subsubsection{Exclusion Criteria}

(i) Those neonates with mothers who were seriously ill

(ii) Those neonates whose mothers were not willing to give information

(iii) Deliveries of unknown gestational age

2.6. Sample Size and Sampling Technique. A sample size of 366 was calculated using single population proportion formula using a $35.7 \%$ proportion of 5 th minute low Apgar score from previous study in Ethiopia [20] at a 95\% confidence limit, 5\% margin of error, and correction formula. Consecutive sampling technique was used.

$$
n=\frac{\left(z_{\alpha / 2}\right)^{2} \cdot p q}{d^{2}}
$$

where $n$ is the sample size, $Z^{?} /_{2}$ is the confidence interval $=1.96, P$ is prevalence $=35.7 \%$, and $d$ is margin of error $=5 \%$.

With the above assumptions, the calculated sample size is 352 .

Since the estimated number of deliveries was less than 10,000 , we use correction formula.

$$
\mathrm{nf}=n /\left(1+\frac{n}{N}\right)
$$


$\mathrm{nf}$ is the final sample size for the targeted population, $n$ is the calculated sample size (352), and $N$ is the total targeted population (6000).

Then, the final sample size according to these equation yields 333 , and adding $10 \%$ for nonresponse (33), it becomes 366 .

\subsection{Study Variables}

\subsubsection{Operational Definition}

(i) Fifth minute Apgar score: Apgar score of newborn neonate at fifth minutes immediately after delivery

2.8. Data Collection Tool and Procedure. The interview questionnaire was adapted after review of different literatures. It consisted of socio-demographic, maternal behavioral factors, maternal obstetric variables, and neonatal characteristics. Completeness of the data and relative accuracy of Apgar score estimation was evaluated by a senior midwife.

Data was collected by two midwifery nurses in the delivery and operation rooms. Training on the standard procedures of Apgar score was provided to data collectors. Each newborn recruited was assessed for Apgar in the 1st, 5th, and 10th minutes after birth and weighed only once soon after delivery.

Apgar score was estimated using five variables, strength and regularity of heart rate (100 beats/minute or more (2 points), less than 100 (1 point), none (0 points)), lung maturity/breathing effort (regular breathing (2 points), irregular and $<30$ breath/minute ( 1 point), none ( 0 points)), muscle tone and movement (active ( 2 points), moderate (1 point), limp (0 points)), skin color/oxygenation (pink (2 points), bluish extremities ( 1 point), totally blue ( 0 points)), and reflex response to irritable stimuli (crying (2 points), whimpering ( 1 point), silence ( 0 points $)$ ). Then, the score of each finding was summed up by an investigator and a score below value seven was considered as low. The data was checked on a daily basis by data collectors and further overseen by the principal investigator for completeness and correctness during collection periods. It was also rechecked during data entry. Training was given for three days on the purpose of data collection, techniques of data collection, and on ways of bias minimization. The questionnaires were prepared in English and translated in to Amharic and retranslated back to English to check its consistency.

2.9. Data Analysis. The collected data were checked for its completeness and then entered to Epi data version 3.1 (Atlanta, US) then exported to SPSS version 20.0 for analysis. Frequencies, means, standard deviation, and percentage were used for the descriptive analysis of data. Chi-square test was done at bivariate level and $P$ value was used to select candidate variables for multivariate analysis. Finally, a 95\% confidence interval was used to assess significance.

2.10. Ethical Consideration. Ethical clearance was obtained from the Institutional Review Board (IRB) of Jimma University. Supportive letter was written to JUMC. The purpose of the study was explained to the neonate mothers briefly. Data
TABLE 1: Sociodemographic characteristics of newborn mothers delivered at Jimma University Medical Center, Southwest Ethiopia, 2018.

\begin{tabular}{lc}
\hline Variables & Frequency $(\%)$ \\
\hline Maternal age & \\
$\leq 20$ years & $28(15.3)$ \\
$21-34$ years & $263(75.6)$ \\
$\geq 35$ years & $47(13.8)$ \\
Marital status & \\
Married & $217(62.4)$ \\
Widowed & $19(5.5)$ \\
Divorced & $48(13.8)$ \\
Single & $64(18.4)$ \\
Maternal education & \\
Illiterate & $103(29.6)$ \\
Primary education & $101(29)$ \\
Secondary education & $94(27)$ \\
Collage and above & $50(14.4)$ \\
Maternal occupation & \\
Housewife & $135(38.8)$ \\
Farmer & $55(15.8)$ \\
Government employee & $88(25.3)$ \\
Nongovernmental employee & $27(7.8)$ \\
Merchant & $41(11.8)$ \\
Others* & $2(0.6)$ \\
\hline
\end{tabular}

${ }^{*}$ Daily laborers.

collection was started after permissions were obtained from hospital managers/medical directors and after a written consent was obtained from children's mothers. Data that were collected from the participants were kept in secured and locked cabinets in order to maintain confidentiality. Voluntary participation was ensured and participants are free to opt out.

\section{Results}

3.1. Sociodemographic Characteristics. A total of 348 neonate/mother pairs were involved in this study yielding a response rate of $95 \%$. About $75.6 \%$ of the mothers were aged 21-34 years. Majority $62.4 \%$ of the participants were married. Nearly one third (29.6\%) of the mothers were illiterate. About $38.8 \%$ of the mothers were housewives. Almost half of $50.9 \%$ the participants were Oromo by ethnicity. About $52.3 \%$ of the participants were from rural area. Majority of $46.6 \%$ participants earn monthly income of 1000-2800 ETB (Table 1).

3.2. Maternal Obstetric-Related Characteristics. Majority $(71.6 \%)$ of the deliveries were spontaneous. Normal duration of labor was reported in $85 \%$ of the cases. Most (93.7\%) of the mothers had history of spontaneous abortion. Regarding mode of delivery, about $42.8 \%$ of deliveries were spontaneous vaginal delivery. About $5.5 \%$ and $7.8 \%$ of the mothers had history of stillbirth and infant death, respectively. ANC 
TABLE 2: Maternal obstetric-related characteristics of newborn mothers delivered at Jimma University Medical Center, Southwest Ethiopia, 2018.

\begin{tabular}{|c|c|}
\hline Variables & Frequency $(\%)$ \\
\hline \multicolumn{2}{|l|}{ Mode of delivery } \\
\hline $\mathrm{SVD}^{9}$ & $149(42.8)$ \\
\hline Instrumental & $98(28.2)$ \\
\hline Cesarean section & $101(29)$ \\
\hline \multicolumn{2}{|l|}{ Condition of labor } \\
\hline Spontaneous & $249(71.6)$ \\
\hline Induced/augmented & $99(28.4)$ \\
\hline \multicolumn{2}{|l|}{ Duration of labor } \\
\hline Normal & $295(85)$ \\
\hline Prolonged & $53(15)$ \\
\hline \multicolumn{2}{|c|}{ History of spontaneous abortion } \\
\hline Yes & $22(6.3)$ \\
\hline No & $326(93.7)$ \\
\hline \multicolumn{2}{|l|}{ History of stillbirth } \\
\hline Yes & $19(5.5)$ \\
\hline No & $329(94.5)$ \\
\hline \multicolumn{2}{|l|}{ History of infant death } \\
\hline Yes & $27(7.8)$ \\
\hline No & $321(92.2)$ \\
\hline \multicolumn{2}{|l|}{ Antenatal care follow-up } \\
\hline Yes & $317(91.1)$ \\
\hline No & $31(8.9)$ \\
\hline \multicolumn{2}{|l|}{ Number of visits } \\
\hline 1 times & $24(6.9)$ \\
\hline 2-3 times & $176(50.6)$ \\
\hline$\geq 4$ times & $117(33.6)$ \\
\hline \multicolumn{2}{|c|}{ Complication during current pregnancy } \\
\hline Yes & $73(21)$ \\
\hline No & $275(79)$ \\
\hline \multicolumn{2}{|l|}{ Type of complication } \\
\hline Preeclampsia & $26(7.5)$ \\
\hline Maternal infection & $18(5.2)$ \\
\hline Antepartum hemorrhage & $7(2)$ \\
\hline Others & $22(30.3)$ \\
\hline \multicolumn{2}{|c|}{ Maternal chronic illness before conception } \\
\hline Yes & $91(27)$ \\
\hline No & $257(73)$ \\
\hline \multicolumn{2}{|l|}{ Type of chronic illness } \\
\hline Hypertension & $33(70.2)$ \\
\hline Diabetes & $20(42.5)$ \\
\hline Both & $3(6.3)$ \\
\hline
\end{tabular}

SSD: spontaneous vaginal delivery.

follow-up was reported in $91.1 \%$ of the mothers. Almost half (50.6\%) of the mothers attended ANC 2-3 times. One-fifth of the mothers had history of complication during current pregnancy. About $27 \%$ of the mothers had history of chronic illness during pregnancy (see Table 2).
TABLE 3: General neonatal characteristics of newborn delivered at Jimma University Medical Center, Southwest Ethiopia, 2018.

\begin{tabular}{lc}
\hline Variables & Frequency $(\%)$ \\
\hline Sex of neonate & $170(48.9)$ \\
Male & $178(51.1)$ \\
Female & \\
Gestational age at birth & $225(64.7)$ \\
Term & $62(17.8)$ \\
Preterm & $61(17.5)$ \\
Postterm & \\
Birth order & $76(21.8)$ \\
First & $118(33.9)$ \\
Second & $154(44.3)$ \\
Third and above & \\
Presentation at birth & $226(65)$ \\
Vertex & $122(35)$ \\
Nonvertex & \\
$5^{\text {th }}$ minute APGAR score & \\
$<7$ & $40(11.5)$ \\
$\geq 7$ & $308(88.5)$ \\
Birth weight (kg) & \\
VLBW & $1(0.2)$ \\
LBW & $21(6)$ \\
NBW & $43(12.3)$ \\
\hline
\end{tabular}

TABLE 4: Behavioral and nutritional characteristics of newborn mothers delivered at Jimma University Medical Center, Southwest Ethiopia, 2018.

\begin{tabular}{lc}
\hline Variables & Frequency $(\%)$ \\
\hline Cigarette smoking history & \\
Current & $22(6.3)$ \\
Former & $15(4.3)$ \\
Passive & $47(13.5)$ \\
Never & $264(75.9)$ \\
Khat chewing history & \\
Yes & $56(16.1)$ \\
No & $292(83.9)$ \\
Maternal folic acid use & \\
Yes & $26(7.5)$ \\
No & $322(92.5)$ \\
Maternal alcohol use history & \\
Yes & $59(17.0)$ \\
No & $289(83.0)$ \\
\hline
\end{tabular}

3.3. General Neonatal Characteristics. More than half (51.1\%) of neonates were females and about $44.3 \%$ of them were third order and above. About $64.7 \%$ of neonates were term deliveries. Regarding their presentation, $65 \%$ of them were vertex. Most of $(81.3 \%)$ the neonates had normal birth weight. The 
TABLE 5: Factors associated with low fifth minute Apgar score in newborn delivered at Jimma University Medical Center, Southwest Ethiopia, 2018.

\begin{tabular}{|c|c|c|c|c|c|c|}
\hline \multirow[t]{2}{*}{ Variables } & \multicolumn{2}{|c|}{$\begin{array}{l}\text { Low } 5^{\text {th }} \text { minute } \\
\text { APGAR score }\end{array}$} & \multicolumn{2}{|c|}{ Bivariate analysis } & \multicolumn{2}{|c|}{ Multivariate analysis } \\
\hline & Yes & No & Chi-square $\left(\chi^{2}\right)$ & $P$ value & AOR (95\% CI) & $P$ value \\
\hline \multicolumn{7}{|l|}{ Maternal education } \\
\hline Illiterate & 12 & 91 & \multirow{4}{*}{1.84} & & $0.32(0.05-1.85)$ & 0.205 \\
\hline Primary & 13 & 88 & & 0.113 & $0.33(0.6-1.88)$ & 0.216 \\
\hline Secondary & 12 & 82 & & & $0.36(0.05-2.26)$ & 0.36 \\
\hline Collage and above & 3 & 47 & & 1 & 1 & 1 \\
\hline \multicolumn{7}{|l|}{ Gravidity } \\
\hline Primigravida & 13 & 67 & \multirow{2}{*}{2.31} & 0.129 & $1.66(0.02-118.3)$ & \multirow{2}{*}{0.815} \\
\hline Multigravida & 27 & 241 & & 1 & 1 & \\
\hline \multicolumn{7}{|l|}{ Duration of labor } \\
\hline Normal & 33 & 262 & \multirow{2}{*}{5.63} & 0.211 & $0.24(0.22-0.55)^{* * *}$ & \multirow[t]{2}{*}{$0.022^{*}$} \\
\hline Prolonged & 7 & 46 & & 1 & 1 & \\
\hline \multicolumn{7}{|l|}{ History of stillbirth } \\
\hline Yes & 4 & 15 & \multirow{2}{*}{1.80} & 0.179 & $4.5(0.09-2.20)$ & \multirow[t]{2}{*}{0.326} \\
\hline No & 36 & 293 & & 1 & 1 & \\
\hline \multicolumn{7}{|l|}{ Number of ANC visits } \\
\hline 1 times & 7 & 17 & \multirow{3}{*}{12.34} & \multirow{3}{*}{0.113} & $2.71(0.57-12.89)$ & 0.210 \\
\hline $2-3$ times & 19 & 157 & & & $2.36(0.44-12.57)$ & \multirow[t]{2}{*}{0.314} \\
\hline$>4$ times & 9 & 108 & & & 1 & \\
\hline \multicolumn{7}{|l|}{ Sex of neonate } \\
\hline Male & 13 & 157 & \multirow{2}{*}{4.83} & 0.028 & $1.48(0.57-3.85)$ & \multirow[t]{2}{*}{0.417} \\
\hline Female & 27 & 151 & & 1 & 1 & \\
\hline \multicolumn{7}{|l|}{ Smoking } \\
\hline Current & 1 & 21 & \multirow{4}{*}{5.02} & \multirow{3}{*}{0.172} & $3.31(0.43-25.41)$ & 0.962 \\
\hline Former & 1 & 14 & & & $2.21(0.28-17.32)$ & 0.347 \\
\hline Passive & 2 & 45 & & & $3.55(0.82-15.28)$ & 0.269 \\
\hline Never & 36 & 228 & & 1 & 1 & \\
\hline \multicolumn{7}{|l|}{ Maternal khat use } \\
\hline Yes & 17 & 39 & 2334 & $<0.00$ & $3.21(1.26-8.85)^{* * *}$ & $0.024^{* *}$ \\
\hline No & 23 & 269 & 25.04 & 1 & 1 & \\
\hline Presentation & & & & & & \\
\hline Vertex & 23 & 203 & 1468 & 0.014 & $0.85(0.17-1.52)$ & 0.216 \\
\hline Non-vertex & 17 & 105 & 14.08 & 1 & 1 & \\
\hline Condition of labor & & & & & & \\
\hline Spontaneous & 25 & 224 & 725 & 0.196 & $0.45(0.22-3.41)$ & 0.082 \\
\hline Induced & 15 & 84 & 1.25 & 1 & & \\
\hline Birth weight & & & & & & \\
\hline Low & 18 & 4 & 38 & 0.011 & $1.65(1.02-3.11)^{* * *}$ & $0.048^{* *}$ \\
\hline Normal & 22 & 304 & ונ.93 & 1 & & \\
\hline
\end{tabular}

${ }^{* * *}$ Statistically significant.

proportion of low fifth minute Apgar score was 11.5\% (see Table 3).

3.4. Behavioral and Nutritional Characteristics. About 13.5\% of the mothers had passive smoking history, $16.1 \%$ had Khat chewing history, and 17\% had alcohol use history. Folic acid use was reported by $7.5 \%$ of the mothers (see Table 4 ).
3.5. Factors Associated with Low Fifth Minute Apgar Score. From bivariate analysis, eleven variables were candidates $(P$ value $<0.25)$ for multivariate regression analysis: maternal education ( $P$ value, 0.113$)$, gravidity ( $P$ value, 0.129$)$ : duration of labor ( $P$ value, 0.211$)$, history of stillbirth $(P$ value, $0.179)$, number of ANC visits ( $P$ value, 0.113$)$, sex of neonate ( $P$ value, 0.028$)$, smoking ( $P$ value, 0.172$)$, maternal khat use 
( $P$ value, $<0.00)$, fetal presentation at birth $(P$ value, 0.014$)$, condition of labor ( $P$ value, 0.196$)$, and birth weight $(P$ value, 0.011) (see Table 5).

3.6. Independent Predictors of Low Fifth Minute Apgar Score. Neonates born from mothers who had a normal duration of labor were 24\% likely to have low Apgar score (AOR 0.24; 95\% CI, 0.22-0.55) than those with prolonged duration. Mothers who had history of khat use were 3 times more likely to give birth to babies with low Apgar score than those without khat use $(\mathrm{AOR}=3.21,95 \% \mathrm{CI}: 1.26-8.85)$. Those neonates with low birth weight were 2 times more likely to have low Apgar score than neonates with normal birth weight $(\mathrm{AOR}=1.65,95 \% \mathrm{CI}$ : 1.02-3.11) (see Table 5).

\section{Discussion}

The current study was conducted to assess the prevalence and factors associated with low fifth minute Apgar score among newborn delivered in Jimma University Medical Center. The proportion of low 5th minute Apgar score in this study was $11.5 \%$. This result is in line with another institution-based study in North-West Ethiopia, Gondar [20]. But the current study was lower than a retrospective study done in Southwest Ethiopia, Jimma (35.7\%). The difference could be due to variation in study design and sample size as well as time of study.

According to the current study, prolonged duration of labor is significantly associated with low fifth minute Apgar score. Similar finding is detected by Altman et al. in Sweden [21], by Salustiano et al. in Brazil [6], and by Gudayu in Ethiopia [20]. The reason for low Apgar score could be due to fetal distress resulted from prolonged duration of labor.

Low birth weight is significantly associated with low fifth minute Apgar score in present study; study done by Levy et al. [22] and by Gudayu in Ethiopia share similar finding [20].

Similarly, in current study, maternal khat chewing during pregnancy was significantly associated with low fifth minute Apgar score. Even though there is no study done so far that explained this relationship, the probable reason may be because khat chewing during pregnancy has negative impact on maternal and fetal well-being specifically resulting in neonate with low birth weight [23]; possible effect of maternal khat chewing on neonate was by disrupting normal neural tube development, undifferentiating brain vesicles, and causing incomplete closure of the brain flexures [24].

Postdelivery factors which may affect Apgar scoring and problems or defects in measuring were not considered and taken as limitation of this study. Because the factors affecting the Apgar score can vary from one health facility to other in the same country, multi-set-up study which may be at country level will be conducted in our future study.

\section{Conclusion}

In the current study, about one tenth of newborns had low 5th minute Apgar score. The likelihood of low fifth minute Apgar score were increased with prolonged duration of labor, history of mother's khat use, and low birth weight. Given the adverse impact of low fifth minute Apgar score on neonates, the authors of this study recommend abstinence from khat use and comprehensive interventions to reduce low birth weight.

\section{Abbreviations \\ ENND: Early neonatal death \\ ETB: Ethiopian birr \\ HBW: High birth weight \\ JUMC: Jimma University Medical Center \\ LBW: Low birth weight \\ MDG: Millennium development goal \\ NBW: Normal birth weight \\ SDGs: Sustainable development goals \\ SVD: Spontaneous vaginal delivery \\ VLBW: Very low birth weight.}

\section{Data Availability}

The authors confirm that all data underlying the findings are fully available without restriction. All relevant data are within the manuscript.

\section{Conflicts of Interest}

The authors declare no conflict of interest.

\section{Acknowledgments}

The authors of this study would like to acknowledge JUMC for its kind cooperation in conducting the study. We would also like to pass our sincere gratitude to the participants of this study and data collectors. Finally, we thank Mr. Teshale Ayele Mega and Dula Dessalegn Bosho for their assistance in the data analysis part of this study.

\section{References}

[1] V. Apgar and L. S. James, "Further observations on the newborn scoring system," American Journal of Diseases of Children, vol. 104, no. 4, pp. 419-428, 1962.

[2] A. Grünebaum, L. B. McCullough, B. Arabin, and F. A. Chervenak, "Serious adverse neonatal outcomes such as 5-minute Apgar score of zero and seizures or severe neurologic dysfunction are increased in planned home births after cesarean delivery," PLoS One, vol. 12, no. 3, article e0173952, 2017.

[3] S. Cnattingius, M. Norman, F. Granath, G. Petersson, O. Stephansson, and T. Frisell, "Apgar score components at 5 minutes: risks and prediction of neonatal mortality," Paediatric and Perinatal Epidemiology, vol. 31, no. 4, pp. 328-337, 2017.

[4] V. K. Paul, M. Singh, K. R. Sundaram, and A. K. Deorari, "Correlates of mortality among hospital-born neonates with birth asphyxia," National Medical Journal of India, vol. 10, no. 2, pp. 54-57, 1997.

[5] S. Iliodromiti, D. F. Mackay, G. C. S. Smith, J. P. Pell, and S. M. Nelson, "Apgar score and the risk of cause-specific infant mortality: a population- based cohort study," The Lancet, vol. 384, no. 9956, pp. 1749-1755, 2014. 
[6] E. M. A. Salustiano, J. A. D. B. Campos, S. M. Ibidi, R. Ruano, and M. Zugaib, "Baixos indices de Apgar no quinto minuto de vida em populaçao de baixo risco: fatores maternos e obstetricos e resultados pos-natais," Revista da Associação Médica Brasileira, vol. 58, no. 5, pp. 587-593, 2012.

[7] J. Li, S. Cnattingus, M. Gissler et al., "The 5-minute Apgar score as a predictor of childhood cancer: a population-based cohort study in five million children," BMJ Open, vol. 2, no. 4, article e001095, 2012.

[8] R. Reading, "Joint association of Apgar scores and early neonatal symptoms with minor disabilities at school age," Child: Care, Health and Development, vol. 28, no. 3, pp. 266-267, 2002.

[9] V. Ehrenstein, L. Pedersen, M. Grijota, G. L. Nielsen, K. J. Rothman, and H. T. Sørensen, "Association of Apgar score at five minutes with long-term neurologic disability and cognitive function in a prevalence study of Danish conscripts," BMC Pregnancy and Childbirth, vol. 9, no. 1, p. 14, 2009.

[10] A. Stuart, P. Otterblad Olausson, and K. Källen, “Apgar scores at 5 minutes after birth in relation to school performance at 16 years of age," Obstetrics and Gynecology, vol. 118, 2, Part 1, pp. 201-208, 2011.

[11] H. C. Lee, M. Subeh, and J. B. Gould, "Low Apgar score and mortality in extremely preterm neonates born in the United States," Acta Paediatrica, vol. 99, no. 12, pp. 1785-1789, 2010.

[12] A. G. Phalen, S. Kirkby, and K. Dysart, "The 5-minute Apgar score: survival and short-term outcomes in extremely lowbirth-weight infants," The Journal of Perinatal \& Neonatal Nursing, vol. 26, no. 2, pp. 166-171, 2012.

[13] M. Rüdiger, The TEST-Apgar study-group, N. Braun et al., "Neonatal assessment in the delivery room-Trial to Evaluate a Specified Type of Apgar (TEST-Apgar)," BMC Pediatrics, vol. 15, no. 1, p. 18, 2015.

[14] J. Lagatta, K. Yan, and R. Hoffmann, "The association between 5-min Apgar score and mortality disappears after $24 \mathrm{~h}$ at the borderline of viability," Acta Paediatrica, vol. 101, no. 6, pp. e243-e247, 2012.

[15] W. Boyce, N. Razaz, W. T. Boyce et al., Five-minute Apgar score as a marker for developmental vulnerability at 5 years of age, UCSF, 2016.

[16] WHO, World Health Statistics 2016: monitoring health for the SDGs, World Health Organization Geneva, 2016.

[17] N. Golding, R. Burstein, J. Longbottom et al., "Mapping under5 and neonatal mortality in Africa, 2000-15: a baseline analysis for the Sustainable Development Goals," The Lancet, vol. 390, no. 10108, pp. 2171-2182, 2017.

[18] Y. Assefa, W. V. Damme, O. D. Williams, and P. S. Hill, "Successes and challenges of the millennium development goals in Ethiopia: lessons for the sustainable development goals," BMJ Global Health, vol. 2, no. 2, article e000318, 2017.

[19] L. Lehtonen, A. Gimeno, A. Parra-Llorca, and M. Vento, "Early neonatal death: a challenge worldwide," in Seminars in Fetal and Neonatal Medicine, pp. 153-160, Elsevier, 2017.

[20] T. W. Gudayu, "Proportion and factors associated with low fifth minute Apgar score among singleton newborn babies in Gondar University Referral Hospital; North West Ethiopia," African Health Sciences, vol. 17, no. 1, pp. 1-6, 2017.

[21] M. Altman, A. Sandström, G. Petersson, T. Frisell, S. Cnattingius, and O. Stephansson, "Prolonged second stage of labor is associated with low Apgar score," European Journal of Epidemiology, vol. 30, no. 11, pp. 1209-1215, 2015.
[22] B. T. Levy, J. D. Dawson, P. P. Toth, and N. Bowdler, "Predictors of neonatal resuscitation, low Apgar scores, and umbilical artery $\mathrm{pH}$ among growth-restricted neonates," Obstetrics and Gynecology, vol. 91, no. 6, pp. 909-916, 1998.

[23] Department of Obstetrics and Gynecology, Assiut University, Egypt, and M. A. Abdel-Aleem, "Khat chewing during pregnancy: an insight on an ancient problem impact of chewing Khat on maternal and fetal outcome among Yemeni pregnant women," Journal of Gynecology \& Neonatal Biology, vol. 1, no. 2, pp. 1-4, 2015.

[24] A. S. Abou-Elhamd, H. Ageely, M. Abu-Elmagd, and A. E. Zayed, "Catha edulis Forsk Mediates Embryotoxic Effects in Rats: An Experimental Study," International Journal of Morphology, vol. 36, no. 3, pp. 1087-1094, 2018. 